\title{
MODELING OF PROCESS PARAMETERS AND ANALYSIS OF EFFECT OF VARIABLES IN THE DEAD BURNING OF MAGNESITE IN ROTARY KILN
}

\author{
B. K. CHAKRABARTI \\ Department of Materials \& Metallurgical Engg. \\ National Institute of Foundry \& Forge Technology \\ Hatia, Ranchi-834003. Jharkhand. \\ E-mail: bijoy_2000in@yahoo.com
}

\begin{abstract}
The challenges of improving sintered $\mathrm{MgO}$ raw materials with special high temperature properties demand higher temperature calcination. In the process of dead burning of magnesite (DBM) in rotary kiln, the heat expenditures were found to be mainly due to dead burning of magnesite, loss through exhaust gases, loss through kiln shell by radiation \& convection, clinker exit etc. The calcination process is highly energy intensive and involves various interdependent variable factors. An attempt was made to build a model and a screening design of experiment was performed with few process variables to identify the greatest effect of variables on the response quality. The design variables chosen were raw magnesite (RM) feed rate, kiln rotation (RPM), fuel consumption and burning zone temperature (BZT). The response variables were exit gas temperature and density of dead burnt magnesite (DBM). A fractional factorial design was used to keep the number of experimental runs to a minimum. ANOVA and normal plots were used to evaluate the effects of different variable factors on the sensory/response properties. The Experimental Design, ANNOVA, Response surface etc. given an insight of dead burning of magnesite in rotary kiln. This work had enabled us to correlate the BZT, RPM, RM feed with the exit gas temp and density of magnesite produced. The result opens up an avenue to look into the optimum region of operations within the ranges of variables considered in order to minimize the exhaust gas temp. and to maximize the density of the DBM produced..
\end{abstract}

Keywords: Dead Burning of Magnesite, Rotary kiln, Modeling \& DOE

\section{Introduction}

The ceramic and refractory industries are the big energy consumers ${ }^{1,2,3}$, where the thermal energy constitutes an important part of the manufacturing costs. Proper utilization and conversion of energy plays an important role in the energy management of any system. DBM production in rotary kiln involves consumption of an alarming amount of energy, where thermal energy constitutes an important part of the manufacturing costs. The success of the dead burning process of magnesite rests on proper controlling of the large number of variable factors responsible for the manufacture of DBM. However in order to visualize optimum out put it is necessary to segregate the important factors which may be directly and greatly responsible for the success of the process. If conservation of energy of the process is of concern then obvious step would be to aim at higher quality of DBM at a lesser energy consumption. An energy campaign of the kiln 
system shows ${ }^{4,5,6}$ that the potential heat loss areas are through kiln shell, chamber exit gas, clinker exit etc. Due to high exit gas temperature and high volume the heat loss was assumed to be quite considerable amount. Therefore, exit gas temperature was considered as one of the response variables. The quality of DBM may be visualized in terms of its sintering, grain growth, crystalline size, Sp.gravity etc. In the present work the specific gravity had been chosen as the other response variable.

Multivariate Data Analysis refers ${ }^{7,8,9}$ to statistical technique used to analyze data that arises from more than one variable. This essentially models in reality where each situation, product, or decision involves more than a single variable. Despite the quantum of data available, the ability to obtain a clear picture of what is going on and make intelligent decisions is a challenge. When available information is stored in database tables containing rows and columns, Multivariate Analysis can be used to process the information in a meaningful fashion.

With the use of process data we can predict various effects of variables on responses and also define optimized solutions to the process. Factorial design is an approach to perform any experiment for analysis. DOE \& ANNOVA, are various techniques used to analyze multivariate data and depict response patterns.

We had used UNSCRAMBLER-9 software package of CAMO Softwares Ltd. to create factorial design and analyze effect of variables on responses.

Experimental design is aimed precisely at solving the problems. in a situation where experiments are costly and, determines which variables are important $\&$ provides more information, and thus will have to be performed with higher priority. The advantage of designing experiments is that one gains control over data distribution, and ensures further analysis.

\section{Data Acquisition \& Kiln Description}

\subsection{Description of the kiln system and data acquisition}

$\begin{array}{ll}\text { Process } & : \text { Dry process. } \\ \text { Type } & : \text { Rotary. } \\ \text { Kiln Length } & : \text { metres. } \\ \text { Kiln Diameter } & : \text { O.D }=2.575 \\ \text { Inclination } & : 3 \% \\ \text { Fuel Type } & : \text { LSHS (Low sulfur heavy stock). } \\ \text { Calorific Value of the Fuel } & : 10800 \text { k.cals / Kg. } \\ \text { Fuel / DBM } & : 0.185 . \\ \text { Average Exit gas temperature } & : 235^{\circ} \mathrm{C} . \\ \text { Atmospheric temperature } & : 30^{\circ} \mathrm{C} .\end{array}$

Data acquisition and utilization of the data needs proper attention, since there are certain variable factors which influences the results very much. 


\section{Experimental}

There are many variable factors involved in dead burning of magnesite in a rotary kiln.. However, based on data acquisition and the work as reported ${ }^{4,5,6}$ the variable factors chosen in this work were Raw magnesite (RM) feed rate, kiln rotation (RPM) and burning zone temperature (BZT) and estimated their effect on two responses viz, Sp.gravity of DBM and exit gas temperature. Sp.gravity of magnesia influences the quality of product and exit gas temperature influences the energy efficiency of the process. UNSCRAMBLER-9 statistical software package was used to design our experiment. Experimental design was made with two levels (upper and lower limits) of the input variables were performed with two centre sample.

Table 1: Lower and Upper limit of the input variables.

\begin{tabular}{lll}
\hline Variables & Lower limit & Upper limit \\
\hline Raw material feed & 10080 & 10320 \\
Specific rotational speed & 60 & 80 \\
Burning zone temperature & 1550 & 1650 \\
\hline
\end{tabular}

Table 2: The Data table of Design matrix.

\begin{tabular}{llllll}
\hline Run & $\begin{array}{l}\text { RM feed }(\mathrm{kg} / \mathrm{hr}) \\
{[\mathrm{A}]}\end{array}$ & $\begin{array}{l}\text { RPM (seconds) } \\
{[\mathrm{B}]}\end{array}$ & $\begin{array}{l}\mathrm{BZT}\left({ }^{\circ} \mathrm{c}\right) \\
{[\mathrm{C}]}\end{array}$ & $\begin{array}{l}\text { Exit temp. } \\
\left({ }^{\circ} \mathrm{c}\right)\end{array}$ & $\begin{array}{l}\text { Sp.gravity } \\
(\mathrm{g} / \mathrm{cc})\end{array}$ \\
\hline 1 & 10080 & 60 & 1550 & 230.0 & 3.250 \\
2 & 10320 & 60 & 1550 & 220.0 & 3.200 \\
3 & 10080 & 80 & 1550 & 228.0 & 3.350 \\
4 & 10320 & 80 & 1550 & 215.0 & 3.300 \\
5 & 10080 & 60 & 1650 & 235.0 & 3.450 \\
6 & 10320 & 60 & 1650 & 240.0 & 3.350 \\
7 & 10080 & 80 & 1650 & 240.0 & 3.452 \\
8 & 10320 & 80 & 1650 & 235.0 & 3.380 \\
9 & 10200 & 70 & 1600 & 230.5 & 3.332 \\
10 & 10200 & 70 & 1600 & 231.5 & 3.328 \\
\hline
\end{tabular}

Table 3: Analysis of Effect shows Significant/Non significant Effect

\begin{tabular}{lll}
\hline Variables & Exit Gas Temp & Sp.gravity \\
\hline RM Feed(A) & $(-)$ Ve & NS \\
SPR(B) & NS & NS \\
BZ Temp(C) & + & ++ \\
\hline
\end{tabular}


Table 4: ANOVA Table where Y-var is Exit Temp.

\begin{tabular}{llllll}
\hline Summary & SS & DF & MS & F-ratio & p-value \\
\hline Model & 437.500 & 4 & 109.375 & 15.670 & 0.0049 \\
Error & 34.900 & 6.980 & & & \\
Adjusted Total & 472.400 & 9.0 & 52.489 & & \\
Intercept & $6.03 \mathrm{e}+05$ & 1 & $6.03 \mathrm{e}+05$ & $8.64 \mathrm{e}+04$ & 0.000 \\
RM Feed & 253.125 & 1 & 253.125 & 36.264 & 0.0018 \\
SPR & 28.125 & 1 & 28.125 & 4.029 & 0.1010 \\
BZTemp. & 153.125 & 1 & 153.125 & 21.938 & 0.0054 \\
\hline
\end{tabular}

Table 5: ANOVA Table where Y-var is Sp. Gravity.

\begin{tabular}{llllll}
\hline Summary & SS & DF & MS & F-ratio & p-Value \\
\hline Model & $5.265 \mathrm{e}-02$ & 4 & $1.316 \mathrm{e}-02$ & 21.938 & 0.0023 \\
Error & $3.00 \mathrm{e}-03$ & 5 & $6.00 \mathrm{e}-04$ & & \\
Adjusted total & $5.56 \mathrm{e}-02$ & 9 & $6.183 \mathrm{e}-03$ & & \\
Intercept & 114.58 & 1 & 114.58 & $1.910 \mathrm{e}+05$ & 0.000 \\
RM Feed & $1.512 \mathrm{e}-03$ & 1 & $1.512 \mathrm{e}-03$ & 2.521 & 0.1732 \\
SPR & $1.250 \mathrm{e}-05$ & 1 & $1.250 \mathrm{e}-05$ & $2.083 \mathrm{e}-02$ & 0.8908 \\
BZTemp & $4.961 \mathrm{e}-02$ & 1 & $4.961 \mathrm{e}-02$ & 82.688 & 0.0003 \\
\hline
\end{tabular}
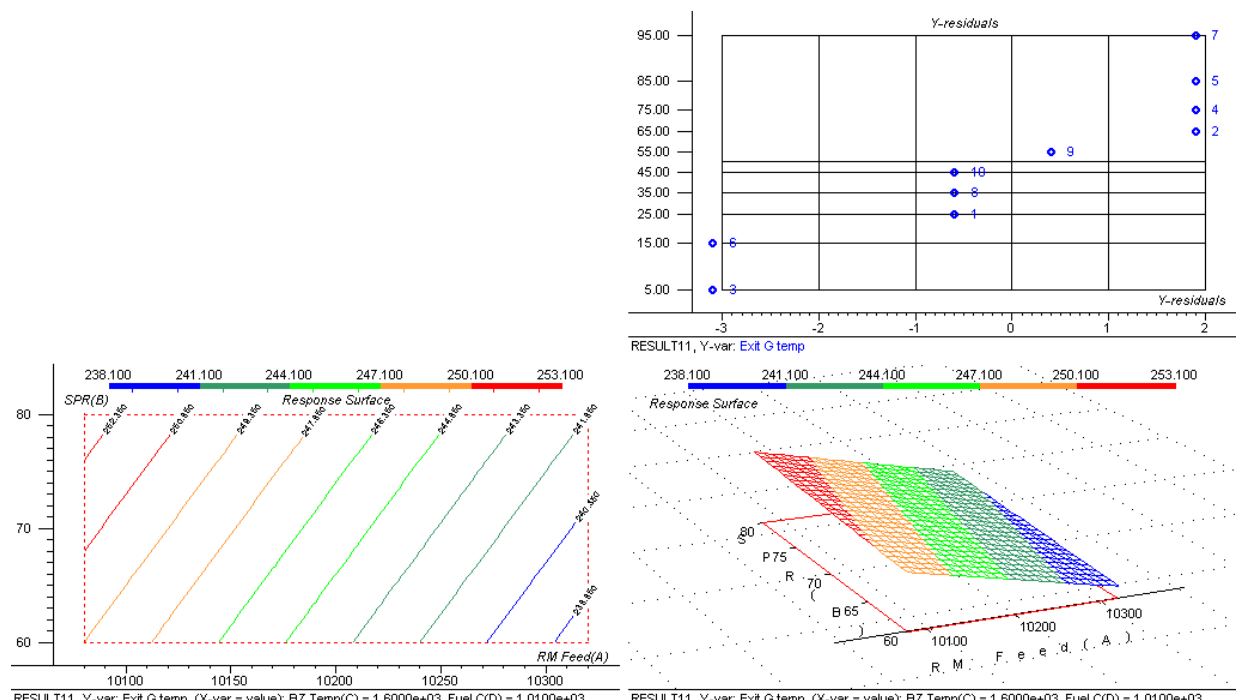

Fig. 1: Response Surface Plot: Y-var: Exit Temp 


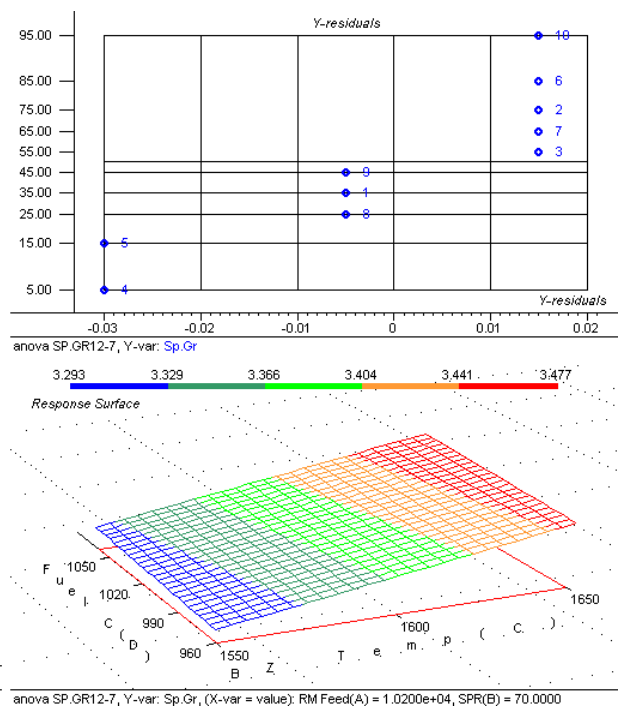

Fig. 2: Response Surface Plot:

Y-Var: Sp.Gravity
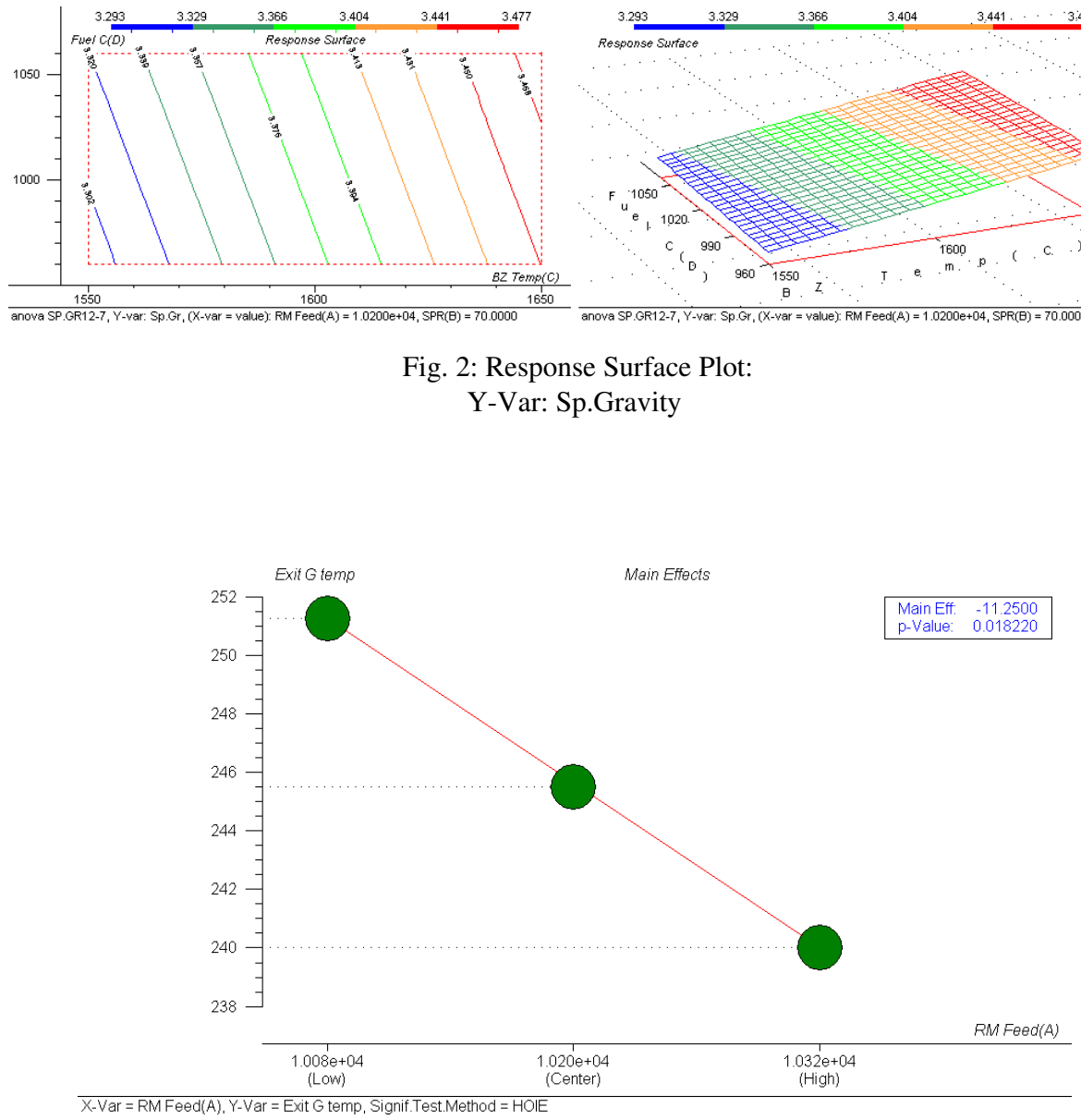

Fig. 3: Main Effects Plot RM Feed vs Exit Gas Temp. 


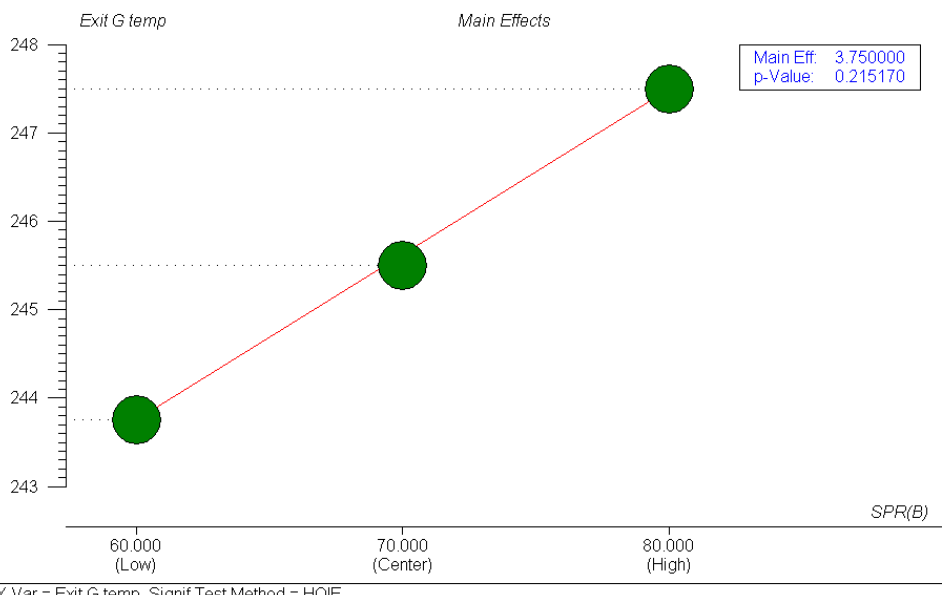

Fig. 4: Main Effects Plot of Kiln Rotation vs Exit Gas Temp

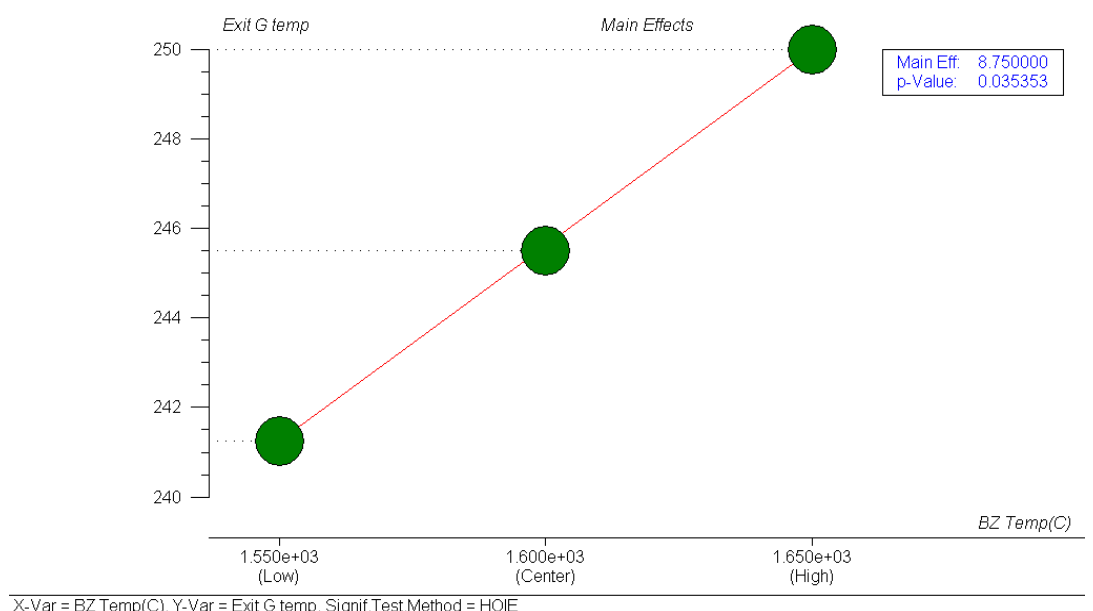

Fig. 5: Main Effects Plot of Burning Zone Temperature vs Exit Gas Temp 


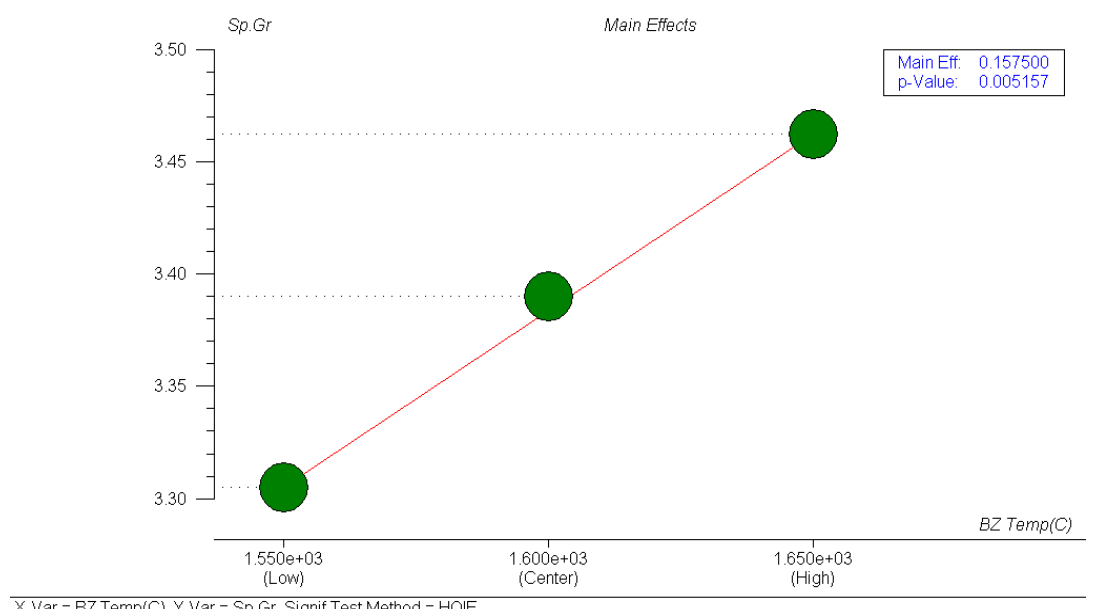

Fig. 6: Main Effects Plot of Burning Zone Temperature vs Specific Gravity.

\section{Results and Discussions}

Main effect plot depicts:

- Exit gas temperature decreases as the raw material feed increases as shown in fig.3. Exit temp has been found to increase as the time of rotation of the kiln increases as shown in fig. 4 .

- Exit gas temperature increases with increase in burning zone temperature shown in fig. 5.

- Fig. 6 illustrates that the specific gravity of DBM increases as the burning zone temperature increases.

\section{Conclusion}

There are many process variables for dead burning of magnesite in rotary kiln. However, due to complexity involved in data acquisition \& exeperiments only three variables were taken into account. Numerous other possibilities and combinations of variables and responses may be aimed at.

The Experimental Design, ANNOVA \& Response surface, main effect plots etc. given an insight into the interactions among variable factors in the dead burning of magnesite in rotary kiln. This work had enabled to correlate the BZ. Temp., RPM, RM feed with the exit gas temp and sp. Gravity of magnesite produced. Table 2. Describes details of data correlating various input factors and response data. Analysis of main effect plots fig.3 to fig.6 illustrates that exit gas temperature decreases as the raw material feed increases and rotational speed increases. The exit gas temperature increases with increase in burning zone temperature. Main effect plot for Sp. gravity response shows that Specific gravity increases as the burning zone temperature increases. Results 
obtained in the work was an outcome of systematic approach towards data acquisition and utilization of the same. However, while comparing the results it has to be kept in mind that the kiln can be judged only after considering the approximations and boundary conditions which were applied.. A proper monitoring of the kiln is extremely essential so that the above factors could be regulated properly. This type of work provides data and appropriate informations to the management of the company about how the units have been functioning.

\section{References}

1. John D. Morgan, Mc Kelvey, Ceramics: Energy Update, a report from $79^{\text {th }}$ Annual Meeting of American Ceram. Society, J. Am. Ceram. Soc.Bull,56 (1977) p-586.

2. Clifford Storey, Energy and the refractories industry, Refractories Journal, 6 (1977)p-26-28.

3. I.K.Smithson, Fuel and energy economy in industry, Tans. British Ceram. Soc.74 (6) 1975, p203.

4. "Energy conservation \& management in refractory burning units."- B.K.Chakrabarti, Presented in the technical session and published in the proceedings of the $65^{\text {th }}$ annual session of the Indian Ceramic Society, 2002.

5. "Investigations on heat loss through the kiln shell in magnesite dead burning process- a case study"- B.K.Chakrabarti, Journal of Applied Thermal Engineering, 22(2002)1339-45.

6. "Studies on the heat transfer behaviour in a magnesite kiln and its assessment"B.K.Chakrabarti, Journal of High Temperature Materials \& Processes, London, Volm.21, No.4, 2002. P187-194.

7. Montgomery, D. C. "Design and Analysis of Experiments", Wiley, NY (2004)

8. Dean A. and Voss D. (1999) "DESIGN AND ANALYSIS OF EXPERIMENT" SPRINGER TEXT in statistics, NEW YORK.

9. T. W. Anderson, "An Introduction to Multivariate Statistical Analysis", 2nd Edition (New York: John Wiley \& Sons, 1984). 